\title{
Clinical Study on Risk Factors and Fetomaternal Outcome of Severe Preeclampsia in Bangabandhu Sheikh Mujib Medical University
}

\author{
Aklima Sultana ${ }^{1}$ \\ Lutfun Nahar Begam Koli ${ }^{1}$ \\ Syeda Sayeeda ${ }^{2}$
}

${ }^{1}$ Department of Obstetrics and Gynaecology Chattagram Maa-O-Shishu Hospital Medical College Chittagong, Bangladesh.

${ }^{2}$ Department of Obstetrics and Gynaecology Bangabandhu Sheikh Mujib Medical University Dhaka, Bangladesh.
*Correspondence to:

\section{Dr. Aklima Sultana}

Assistant Professor

Department of Obstetrics and Gynaecology Chattagram Maa-O-Shishu Hospital Medical College Chittagong, Bangladesh.

Email: draklimasultana@gmail.com Mobile : +8801816350046

\begin{abstract}
Background: Preeclampsia (PE) especially severe or early PE, is a leading cause of morbidity and mortality among the mothers and infants.To determine the maternal risk factors and fetomaternal outcome of severe preeclampsia. Methods: It was a case control study, done in a tertiary care hospital among 100 patients with severe preeclampsia and normal pregnant women admitted. Sampling technique were consecutive sampling methods. Singleton pregnancy between 28 to 40 weeks of gestation with severe preeclampsia were selected as study patients. Written informed consent was obtained. A questionnaire was completed for each patient including patient's age, gestational age, parity, History of hypertension in family, weight and Body Mass Index (BMI). Maternal complications before or after delivery, and perinatal outcome were also be recorded in the data sheet. Data was analyzed by SPSS-20. Results: Among the 50 cases and 50 controls regarding different risk factors age $>34$ years, BMI, history of precelampsia, were found significant $(\mathrm{p}<0.05)$ between two groups. Among the case group, patients developed eclampsia 2(4.0\%) abruptio placenta 3(6.0\%) HELLP syndrome 2(4.0\%) ascites $4(8 \%)$ and oliguria1(2.0). But none of the control group had developed these types of complications. In case group $7(14.0 \%)$ patients developed PPH and pulmonary oedema $3(6.0 \%)$. In control group 5(10.0\%) developed PPH and 1(2.0\%) developed pulmonary oedema. It was observed that, in case group $5(12.5 \%)$ babies had very low birth weight $(<1.5 \mathrm{~kg})$ but not in control group. twenty one $(52.5 \%)$ of the babies had low birth weight $(<2.5 \mathrm{~kg})$ in case group and $8.0 \%$ of babies had low birth weight in control group. Most $56.0 \%$ of the neonates had APGAR score 4-6 at 1 minute in case group and $12(24.0 \%)$ in control group. In case group 17(34\%) babies developed birth asphyxia and $15(30.0 \%)$ of babies developed prematurity, where in control group $7(14.0 \%)$ babies developed birth asphyxia and $3(6.0 \%)$ of babies developed prematurity. $32(80.0 \%)$ newborn needed admission in neonatal care unit in case group and $10(20.0 \%)$ in control group $(\mathrm{p}<0.05)$. Take baby in home safely in $35(70.0 \%)$ in cases group and $50(100.0 \%)$ in control group. Early neonatal death was found in $5(10.0 \%)$ in case group and not found in control group. Still birth was $10(20.0 \%)$ case group and not found control group $(\mathrm{p}<0.05)$. Conclusion: Preeclampsia is a leading cause of both fetal and maternal morbidity and mortality in the developing countries. Maternal and fetal outcome are worse in severe preeclampsia.
\end{abstract}

Key words: Fetomaternal outcome; Preeclampsia; Pregnant women; Morbidity and mortality.

\section{INTRODUCTION}

Preeclampsia is hypertension associated with proteinuria greater than $0.3 \mathrm{~g} / \mathrm{L}$ after 20 wks of gestation ${ }^{1}$. Pre-eclampsia may be mild and severe.

Mild pre-eclampsia- if the systolic blood pressure is less than $160 \mathrm{mmHg}$ and the diastolic blood pressure is less than $110 \mathrm{mmHg}$ and the patient does not have any of the signs and symptoms associated with severe pre-eclampsia. 


\section{Severe Pre-eclampsia Defines}

i) Systolic blood pressure of $160 \mathrm{mmHg}$ and or diastolic blood pressure of $110 \mathrm{mmHg}$ on two occasions at least 6 hours apart while the patient is in bed rest

ii) Proteinuria of $5 \mathrm{~g}$ or higher in a 24-hour urine specimen or $3+$ or greater on two random urine samples collected at least 4 hours apart

iii) Oliguria of less than $500 \mathrm{ml}$ in 24 hours

iv) Cerebral or visual disturbances

v) Pulmonary edema or cyanosis

vi) Epigastric or right upper quadrant pain

vii) Impaired liver function

xiii) Thrombocytopenia

ix) Fetal growth restriction (Fernando, 2007).

Preeclampsia affects $2-10 \%$ of pregnant women worldwide and eclampsia $0.03-0.05 \%{ }^{2}$. The reported incidences of eclampsia in developing countries are between 0.1 to 0.2 per 100 deliveries while in the Western world is 1 in 2000 to 1 in $3000^{3,4}$.

It is estimated that worldwide $13 \%$ of maternal mortality is due to hypertensive disorders of pregnancy but it is much higher in developing countries where the estimates are between $20-80 \%$ in Africa and Latin America ${ }^{5,6}$.

Medical condition such as renal disease, chronic hypertension or high blood pressure at booking and chronic autoimmune disease are risk factors for pre-eclampsia. Other factors are thrombophilias and insulin resistance ${ }^{7}$. Change of paternity in multiparous women has been associated with pre-eclampsia and eclampsia ${ }^{8}$.

In low socio economic status of women doubled the risk of pre eclampsia and eclampsia ${ }^{9}$. A study in Australia found working women compared to non working ones had a higher risk of developing pre-eclampsia and eclampsia (Najman et al 1989). This may be related to the stress that women get during work. Black ethnicity has been reported as risk factor for preeclampsia in USA and $\mathrm{UK}^{10}$.

Pre-eclampsia, though preventable to some extent when severe it leads to feto-maternal death. Although pre-eclampsia is not totally preventable, its early detection and proper treatment can prevent it from its complications. However, in Bangladesh antenatal care service is provided by various levels of health care providers, though their knowledge and skill may vary. For women with preexisting hypertension and/or proteinuria, the diagnosis of severe pre-eclampsia can be more difficult, but new-onset severe hypertension or proteinuria or development of other clinical or laboratory findings of severe pre-eclampsia are suggestive of pre-eclampsia in this setting.

\section{MATERIALS AND METHODS}

It was a case control study, done in Bangabandhu Sheikh Mujib Medical University (BSMMU) Dhaka during a period of six months from March 2014 to August 2014. The study population was 50 women with severe preeclampsia and 50 women with normal pregnancy admitted in the Department of Obstetrics and Gynaecology in BSMMU. Singleton pregnancy between 28 to 40 weeks of gestation with severe preeclampsia were selected as study patients. Those preeclampsia patients are included whose, systolic blood pressure is $\geq 160 / \mathrm{mmHg}$ and or diastolic blood pressure is $\geq 110 \mathrm{mmHg}$ or proteinuria $>5$ gm/day, or oliguria of less than $500 \mathrm{ml}$ in 24 hours, cerebral or visual disturbances, pulmonary edema or cyanosis, epigastric or right upper quadrant pain, impaired liver function, thrombocytopenia, fetal growth restriction were selected as case and normotensive patients with above gestational age were selected as control. Patient with chronic hypertension, diagnosed case of chronic renal failure, diagnosed case of hepatic disease,patient with cardiovascular disease, patient with haemorrhagic disorders, psychotic patients and patients of systemic lupus erythromatosis were excluded from the study. A questionnaire was completed for each patient including patient's age, gestational age, parity, hypertension in family, previous $\mathrm{h} / \mathrm{o}$ preeclampsia weight and Body Mass Index (BMI). Then measurment of blood pressure and proteinuria was recorded in data sheet. Maternal complications before or after delivery as well as perinatal outcome were also recorded. Statistical analyses were carried out by using the Statistical Package for Social Sciences version 20 for Windows (SPSS Inc. Chicago, Illinois, USA).

\section{RESULTS}

Table 1: Distribution of the study patients according to maternal risk factors $(\mathrm{n}=100)$.

\begin{tabular}{|c|c|c|c|c|c|c|}
\hline Maternal risk factors & $\begin{array}{l}\text { Case } \\
(n=50)\end{array}$ & $\begin{array}{l}\text { Control } \\
(\mathrm{n}=50)\end{array}$ & $\mathrm{OR}$ & $95 \% \mathrm{CI}$ & & $\begin{array}{c}\mathrm{p} \\
\text { Value }\end{array}$ \\
\hline & $\mathrm{n}$ & n & & Lower & Upper & \\
\hline Age $>34$ years & 15 & 4 & 4.93 & 1.36 & 19.43 & $0.005^{\mathrm{s}}$ \\
\hline $\operatorname{BMI}\left(>24.9 \mathrm{~kg} / \mathrm{m}^{2}\right)$ & 38 & 25 & 3.17 & 1.25 & 8.16 & $0.007^{\mathrm{s}}$ \\
\hline History of preeclampsia & 13 & 3 & 5.50 & 1.32 & 26.44 & $0.006^{\mathrm{s}}$ \\
\hline Diabetes & 6 & 4 & 1.57 & 0.36 & 7.19 & $0.504^{\mathrm{ns}}$ \\
\hline Low socioeconomic status & 24 & 17 & 1.79 & 0.74 & 4.35 & $0.154^{\mathrm{ns}}$ \\
\hline
\end{tabular}

$\mathrm{s}=$ significant, $\mathrm{ns}=$ not significant, $\mathrm{p}$ value reached from chi square test

Table 1 showing different risk factors where regarding age $>34$ years, 15 patients found in case group and 4 patients in control group. Significant $(\mathrm{p}<0.05)$ difference was found between two groups. Patients had 4.93 times more likely to developed preeclampsia. Regarding BMI, 38 patients had BMI more than 25 in case group and 25 patients in control group. Significant $(p<0.05)$ 
difference was found between two groups. Patients had 3.17 times more likely to developed preeclampsia. Regarding history of precelampsia, 13 patients found in case group and 3 patients in control group. Significant $(\mathrm{p}<0.05)$ difference was found between two groups. Patients had 5.50 times more likely to developed preeclampsia. Other results are mentioned in the table.

Table 2: Distribution of the study patients according to maternal outcome $(n=100)$.

\begin{tabular}{lrrrrr} 
Maternal Outcome & \multicolumn{2}{c}{ Case } & \multicolumn{2}{c}{ Control } & $\begin{array}{c}\text { p } \\
\end{array}$ \\
& \multicolumn{1}{c}{$\mathbf{n}(\mathbf{n}=\mathbf{5 0})$} & \multicolumn{2}{c}{$\mathbf{c}(\mathbf{n}=\mathbf{5 0})$} & Value \\
No complication & 28 & 56.0 & 44 & 88.0 & $0.001^{\mathrm{S}}$ \\
Complication & 22 & 44.0 & 6 & 12.0 & \\
Eclampsia & 2 & 4.0 & 0 & 0.0 & \\
Abruptio placenta & 3 & 6.0 & 0 & 0.0 & \\
PPH & 7 & 14.0 & 5 & 10.0 & \\
Pulmonary oedema & 3 & 6.0 & 1 & 2.0 & \\
HELLP syndrome & 2 & 4.0 & 0 & 0.0 & \\
Ascites & 4 & 8.0 & 0 & 0.0 & \\
Oliguria & 1 & 2.0 & 0 & 0.0 &
\end{tabular}

$\mathrm{s}=$ significant, $\mathrm{p}$ value reached from chi-square test.

Table 2 shows maternal complications of the patients. It was observed that $22(44.0 \%)$ and $6(12.0 \%)$ had complication in case and control group respectively. The difference was statistically significant $(\mathrm{p}<0.05)$ between two groups. Among the case group, $2(4.0 \%)$ patients developed eclampsia, 3(6.0\%) patients developed abruptio placenta, 2(4.0\%) patients developed HELLP syndrome, 4(8\%) patients developed ascites and 1(2.0) patient developed oliguria. But none of the control group had developed these types of complications. The difference was statistically significant $(p<0.05)$ between two groups. In case group 7(14.0\%) patients developed PPH and $3(6.0 \%)$ developed pulmonary oedema. In control group $5(10.0 \%)$ developed PPH and 1(2.0\%) developed pulmonary oedema, these difference were not so significant between two groups.

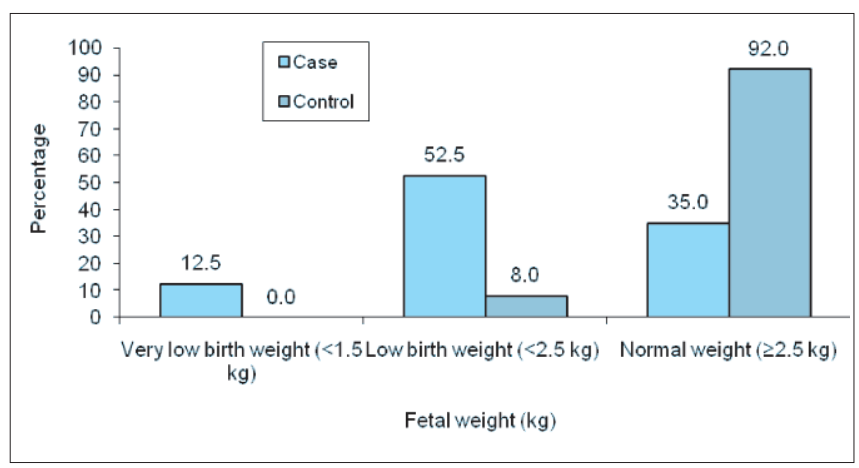

Figure 1: Bar diagram showing fetal weight of the study patients $\left(\mathrm{n}=90^{*}\right)$.

*10 babies were drop out due to still birth
Figure 2 shows the fetal weight of the study patients it was observed that, in case group 5(12.5\%) babies had very low birth weight $(<1.5 \mathrm{~kg})$ but not in control group. twenty one $(52.5 \%)$ of the babies had low birth weight $(<2.5 \mathrm{~kg})$ in case group and $8.0 \%$ of babies had low birth weight in control group. These difference was significantly $(\mathrm{p}<0.05)$ higher in case group. Fourteen $(35.0 \%)$ babies were found normal weight $(\geq 2.5 \mathrm{~kg})$ in case group and 46(92.0\%) in control group.

Table 3: Distribution of the study patients according to APGAR score $(\mathrm{n}=100)$.

\begin{tabular}{|c|c|c|c|c|c|}
\hline \multirow[t]{2}{*}{ APGAR Score } & \multicolumn{2}{|c|}{$\begin{array}{c}\text { Case } \\
(n=50)\end{array}$} & \multicolumn{2}{|c|}{$\begin{array}{c}\text { Control } \\
(n=50)\end{array}$} & \multirow[t]{2}{*}{$\begin{array}{c}\mathbf{p} \\
\text { Value }\end{array}$} \\
\hline & n & $\%$ & n & $\%$ & \\
\hline \multicolumn{6}{|l|}{ At 1 minute } \\
\hline 0 & 10 & 20.0 & 0 & 0.0 & $0.001^{\mathrm{s}}$ \\
\hline $0-4$ & 4 & 8.0 & 0 & 0.0 & \\
\hline $4-6$ & 28 & 56.0 & 12 & 24.0 & \\
\hline $7-10$ & 8 & 16.0 & 38 & 76.0 & \\
\hline \multicolumn{6}{|l|}{ At 5 minutes } \\
\hline $4-6$ & 12 & 30.0 & 3 & 6.0 & $0.002^{\mathrm{s}}$ \\
\hline $7-10$ & 28 & 70.0 & 47 & 94.0 & \\
\hline
\end{tabular}

* 10 babies drop out due to still birth

$\mathrm{s}=$ significant, $\mathrm{p}$ value reached from unpaired t-test.

The above table 5 shows the APGAR score at $1 \mathrm{~min}$ and $5 \mathrm{~min}$ of the delivered babies of the study patients. Most $56.0 \%$ of the neonates had APGAR score 4-6 at 1 minute in case group and $12(24.0 \%)$ in control group. Twelve $(30.0 \%)$ babies had APGAR score 4-6 at 5 minutes in case group and 3(6.0\%) \%) babies had APGAR score 4-6 at 5 minutes in control group. There was statistically significant $(\mathrm{p}<0.05)$ difference was found between two groups.

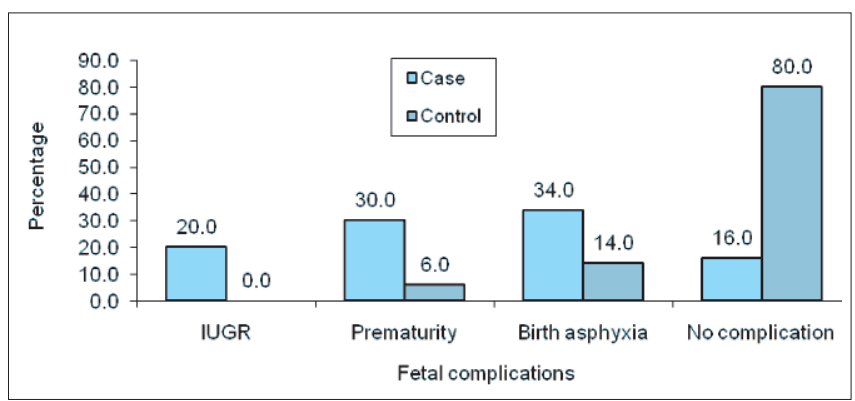

Figure 2: Bar diagram showing fetal complications of the study patients $(\mathrm{n}=100)$.

The above figure 2 shows the fetal complication of the study patients. It was observed that $42(84.0 \%)$ of babies had complication in case group and $10(20 \%)$ of babies had complication in control group. Among them, in case group 17(34\%) babies developed birth asphyxia and $15(30.0 \%)$ of babies developed prematurity, where in control group $7(14.0 \%)$ babies developed birth asphyxia and 3(6.0\%) of babies developed prematurity. The difference was statistically significant $(p<0.05)$ between two groups. In case group IUGR developed in $10.0 \%$ babies, but not this complication found in control group. 


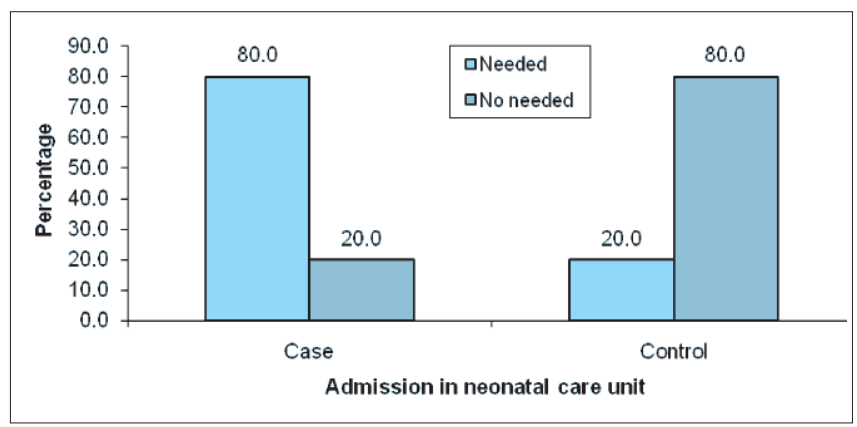

Figure 3 : Bar diagram showing admission in neonatal care unit of the study patients $(\mathrm{n}=90 *)$.

\section{* 10 babies drop due to still birth}

The above figure 3 shows the admission in neonatal care unit of the study patients. $32(80.0 \%)$ newborn needed admission in neonatal care unit in case group and $10(20.0 \%)$ in control group. Statistically significant $(\mathrm{p}<0.05)$ difference was found between two groups in chi square test.

Table 4 : Distribution of the study patients according to perinatal outcome $(n=100)$

\begin{tabular}{lrrrrr} 
Perinatal outcome & \multicolumn{2}{c}{ Case } & \multicolumn{2}{c}{ Control } & p \\
& \multicolumn{1}{c}{$\mathbf{( n = 5 0 )}$} & \multicolumn{2}{c}{$(\mathbf{n}=\mathbf{5 0})$} & value \\
& $\mathbf{n}$ & $\%$ & \multicolumn{1}{c}{$\mathbf{n}$} & $\%$ & \\
Live birth & & & & & \\
Take home alive & 35 & 70.0 & 50 & 100.0 & $0.001 \mathrm{~s}$ \\
Early neonatal death & 5 & 10.0 & 0 & 0.0 & $0.028 \mathrm{~s}$ \\
Still birth & 10 & 20.0 & 0 & 0.0 & $0.001 \mathrm{~s}$ \\
\hline
\end{tabular}

$\mathrm{s}=$ significant, $\mathrm{ns}=$ not significant, $\mathrm{p}$ value reached from chisquare test

The above table 4 shows the perinatal outcome of the study patients. Take baby in home safely in $35(70.0 \%)$ in cases group and $50(100.0 \%)$ in control group. Early neonatal death was found in $5(10.0 \%)$ in case group and not found in control group. Still birth was $10(20.0 \%)$ case group and not found control group. Statistically significant $(\mathrm{p}<0.05)$ difference was between two groups.

\section{DISCUSSION}

This case control study was carried out with an aim to find out the demographic characteristics of patient with severe preeclampsia and of control group to evaluate the maternal risk factors of severe preeclampsia as well as to assess the foeto-maternal outcomes associated with severe preeclampsia and normal pregnant patients.

In this present study it was observed that majority (40.0\%) of the cases were in age group 20-29 years and 50.0\% in control group. Maternal age $>34$ years was found $15(30 \%)$ in case group, and $4(8 \%)$ in control group. The mean age was found $25.8 \pm 5.26$ years with range from 17 to 38 years and $24.15 \pm 3.69$ years with range from 18 to 35 years in case and control group respectively. The mean age difference was not statistically significant $(p>0.05)$ between two groups. Similarly, Roudsari et al showed the mean maternal age was $28.2 \pm 6.6$ years in severe preeclampsia and $26.3 \pm 5.2$ years in controls, which is closely resembled with the present study ${ }^{11}$. Maternal age 35 years was found by the authors was $28.6 \%$ in cases and $21.2 \%$ in controls. Amorim et al reported that a significantly increased average age between cases 30.6 years versus 23.7 years old of the control group, which is higher with the current study ${ }^{12}$. It could be due to geographical variations, racial and ethnic differences, genetic causes and different lifestyle had significant impact to developed Severe preeclampsia in their country.

Many investigators Lee et al Marviel et al reported that obese women, prepregnancy body mass index of more than $24.2 \mathrm{~kg} / \mathrm{m}^{2}$ are risk factors for development of severe preeclampsia ${ }^{13,14}$. In this series it was observed that majority $38(76 \%)$ patients had BMI $>25$ in case group. The mean BMI was $31.4 \pm 7.5 \mathrm{~kg} / \mathrm{m}^{2}$ and $28.7 \pm 6.0 \mathrm{~kg} / \mathrm{m}^{2}$ in case and in control group respectively. The mean BMI was significantly $(\mathrm{p}<0.05)$ higher in case group. Manna done a study in BSMMU and found obese 35.6\% and $22.2 \%$ in case and control group respectively, which is comparable with the current study ${ }^{15}$.

The risk factors for developing preeclampsia are primigravid, age $<20$ yrs or $>35 \mathrm{yrs}$, multiple gestation, family history of preeclampsia, a prior history of preeclampsia, body mass index at or above 35 at first contact, preexisting hypertension or diabetes (Robson 1999 and Sibai, Taslima \& Abdulla 1985). Regarding the maternal risk factors in this current study it was observed that, age $>34$ years significantly 4.93 times increased with $95 \%$ CI $1.36-19.43 \%$ to develope preeclampsia. BMI $\left(>24.9 \mathrm{~kg} / \mathrm{m}^{2}\right)$ had 3.17 times with $95 \%$ CI $1.25-8.16 \%$ more likely to developed preeclampsia. Previous history of precelampsia had 5.50 times with $95 \%$ CI $1.32-26.44 \%$ more likely to developed preeclampsia. However, diabetes, Low socioeconomic status was higher in case group but not statistically significant. Marviel et al have been reported that age more than 34 years, obese women, pregnancy body mass index of more than $24.2 \mathrm{~kg} / \mathrm{m}^{2}$ and urinary tract infection are significantly associated with preeclampsia ${ }^{14}$.

The rate of neonatal complications is markedly increased in those who developed severe preeclampsia in second trimester whereas it is minimal in those with severe preeclampsia beyond 35 weeks gestation. Severe preeclampsia is also associated with increase risk of maternal mortality $(0.2 \%) \&$ increased risk of maternal morbidities $(5.0 \%)$ such as convulsion, pulmonary oedema, acute renal failure, hepatic failure, disseminated intravascular coagulopathy \& stroke. In $10 \%$ cases it leads to HELLP syndrome (Sibai, Villar and Mabie 1990). In another study Stone et al. (1994) obtained that history of preeclampsia OR=11.52 with $95 \%$ CI $5.09-26.09 \%$, BMI $32.3 \mathrm{~kg} / \mathrm{m}^{2}$ $\mathrm{OR}=4.26$ with $95 \%$ CI $2.06-8.81 \%$. The above findings are comparable with the current study. 
In this present study it was observed that $44.0 \%$ of cases and $12.0 \%$ of control had complication, which was significantly $(p<0.05)$ higher in case group. Among the case group, $2(4.0 \%)$ patients developed eclampsia, 3(6.0\%) patients developed abruptio placenta, 2(4.0\%) patients developed HELLP syndrome, 4(8\%) patients developed ascites and 1(2.0) patient developed oliguria. But none of the control group had developed these types of complications. The difference was statistically significant $(\mathrm{p}<0.05)$ between two groups. In case group 7(14.0\%) patients developed PPH and 3(6.0\%) developed pulmonary oedema. In control group 5(10.0\%) developed PPH and $1(2.0 \%)$ developed pulmonary oedema, these difference were not so significant between two groups. Actually in control group one patient developed pulmonary oedema due to fluid over load. In this study done by Gofton et al (2001) and Boriboonhirunsar et al showed PPH $14.3 \%$ and $10.5 \%$ respectively in their case group ${ }^{16}$. Shaheen and Tahir (2008) showed $(2.0 \%)$ eclampsia, (8.0\%) HELLP syndrome. The findings of the above mentioned studies are consistent with the current study. In my study there was no maternal death.

In this current study it was observed that that, in case group $12.5 \%$ babies had very low birth weight $(<1.5 \mathrm{~kg})$ but not in control group. Twenty one $(52.5 \%)$ of the babies had low birth weight $(<2.5 \mathrm{~kg})$ in case group and $8.0 \%$ of babies had low birth weight in control group. These difference was significantly $(p<0.05)$ higher in case group. Fourteen $(35.0 \%)$ babies were found normal weight $(\geq 2.5 \mathrm{~kg}$ ) in case group and $46(92.0 \%)$ in control group. Similarly, Stone et al (1994) found low $(<2500$ g) birth weight was $62.9 \%$ in cases and $6.9 \%$ in controls, which was also significantly $(\mathrm{p}<0.05)$ higher in case group, thus support the present study.

In this series APGAR score was done in all babies delivered by case and control groups. Among the 50 cases, it was observed that APGAR score was done and found 0 in 10 babies due to still birth. Four (8\%) of babies had APGAR score 0-4 at 1 minute in case group who were severely asphyxiated. Twenty eight (56.0\%) of babies in case group had APGAR score 4-6 at 1 minute and $24.0 \%$ of babies had APGAR score 4-6 at 1 minute in control group. In case group $30.0 \%$ of babies had APGAR score $4-6$ at 5 minute and $6.0 \%$ in control group. APGAR score at 1 minute and at 5 minute were significantly $(p<0.05)$ higher in case group then in control group. Similarly, Mansour et al. (2011) mentioned that the babies born to severe preeclampsia group had lower APGAR score at 1 and 5 minutes, than control group $(\mathrm{p}<0.001)$, which support the current study.
In this present study it was observed that $80.0 \%$ newborn needed admission in neonatal care unit in case group, due to prematurity, severe perinatal asphyxia and their complications. Eight $(20.0 \%)$ newborn needed admission in neonatal care unit in control group, due to mild perinatal asphyxia and prematurity. The difference was significantly $(p<0.05)$ higher in case groups. A study done by Das (2012) at BSMMU, Bangladesh found that $79.2 \%$ newborn needed admission in neonatal care unit in case group and $16.0 \%$ in control group. This study finding in consistent with the current study.

In this current study it was observed that take baby in home safely was $70.0 \%$ in case group and $100.0 \%$ in control group. Early neonatal death was found in five $(10.0 \%)$ of the case group due to severe perinatal asphyxia, prematurity and their complications. Ten $(20.0 \%)$ babies were found still birth in case group and 5(10.0\%) babies were found neonatal death in case group, but there were not still birth and neonatal death in control group. The difference was statistically significant $(\mathrm{p}<0.05)$ between two groups. In this study $80.0 \%$ babies were admitted in neonatal care unit in case group and $24.0 \%$ of babies were admitted in neonatal care unit in control group. Stone et al. (1994) reported in their study that neonatal death was found $4.3 \%$ in cases and $0.3 \%$ in controls. The difference was statistically significant $(\mathrm{p}<0.05)$ between two groups in this study. Buchbinder et al and Hauth et al reported that admission to NICU varied from 38.0 to $43.0 \%$ babies born to severe preeclampsia. In another study Buchbinder et al showed admission to NICU was $38.1 \%$ in severe preeclampsia ${ }^{17,18}$. In this study, there was no maternal death ${ }^{17}$.

\section{CONCLUSION}

Preeclampsia is a leading cause of both fetal and maternal morbidity and mortality in the developing countries. Regular antenatal checkup to detect the rapid wt gain or rising BP is very important to prevent preeclampsia. Beside these low dose aspirin \& low molecular wt heparine is useful in high risk women with thrombophilia. Calcium supplement \& other antioxident like Vit E \& C \& balanced diet rich in protein may also reduce the risk of preeclampsia.

\section{DISCLOSURE}

All the authors declared no competing interest. 
REFERENCES

1. Fernando A. Practical Guide to HIGH-RISK PREGNANCY \& DELIVERY. 2007;417.

2. Klonis, M.L. Emergency management of eclampsia and severe pre-eclampsia. Emerg Med. 2003;15:361-368

3. Liskin, L.S. Maternal morbidity in developing countries: a review and comments. Int J Gynaecol Obstet. 1992;37:77-87.

4. Sibai, B.M. Diagnosis and management of gestational hypertension and pre eclampsia. Obstet Gynecol. 2003;102:181-192.

5. Fernando, A. Practical Guide to HIGH-RISK PREGNANCY \& DELIVERY. 3rd edition. 2007;417.

6. Khan, K S, Woojdyla, D Say L. WHO analysis of causes of maternal death: A systematic review. Lancet. 2006;367:1066-1074.

7. Kaaja, R. Predictors and risk factors of preeclampsia. Minerva Ginecol. 2008;60:421-429.

8. Broughton, P.F. Risk factors for pre - eclampsia. N Engl J Med. 2001; 344:925-926.

9. Ceron-Mireles P, Harlow SD, Sanchez-Carrillo CI, Nunez, R.M. Risk factors for pre - eclampsia/ eclampsia among working women in Mexico City. Paediatr Perinat Epidemiol. 2001;15:40-46.

10. Odegard, R.A, Vatten, L.J., Nilsen, S.T. Risk factors and clinical manifestations of pre-eclampsia. Bjog, 2000;107:1410-1416.

11. Roudsari, FV, Ayati, S Ayatollahi H, Esmaeily, H, Hasanzadeh, M, Shahabian, M. et al Comparison of maternal serum Tumor Necrosis Factor-alpha (TNF- $\alpha$ ) in severe and mild preeclampsia versus normal pregnancy. Iranian Journal of Reproductive Medicine. 2009;7(4): 153-156.

12. Amorim, M.M.R, Santos, L.C, Porto, A.M.F, Martins, L.K.D. Risk factors for maternal death in patients with severe preeclampsia and eclampsia. Rev. bras. saúde matern. infant., Recife. 2001;1 (3):237-247.

13. Lee, C.J, Hsieh, T.T, Chiu, T.H. Risk factors for pre - eclampsia in an Asian population. Int J Gynaecol Obstet. 2000;70:327-333.

14. Marviel, P, Touzart, L, Deslandes, V. Risk factors of pre - eclampsia in a single pregnancy. J Gynecol Obstet BioI Reprod Paris. 2008;37:477-482.

15. Manna, F.N., 2008. Study on association of maternal serum triglyceride with preeclampsia. Department of Obstetrics and Gynaecology, Bangabandhu Sheikh Mujib Medical University.

16. Boriboonhirunsarn, D, Talungjit, P, Sunsaneevithayakul, P, Sirisomboon, R. Adverse Pregnancy Outcomes in Gestational. Diabetes Mellitus. J Med Assoc Thai. 2006; 89(4):23-28.

17. Buchbinder, A, Sibai, B.M, Caritis, S, Macpherson, C, Hauth J, Lindheimer, M.D, et al. Adverse perinatal outcomes are significantly higher in severe gestational hypertension than in mild preeclampsia. Am J Obstet Gynecol. 2005;186(1):66-71.

18. Hauth, J.C, Ewell, M.G, Levine, R.J, Esterlitz, J.R, Sibai, B, Curet L.B, et al. Pregnancy outcomes in healthy nulliparas who developed hypertension. Calcium for Pre-eclampsia Prevention Study Group. Obstet Gynecol. 2000;95:24-28. 